Check for updates

Cite this: Chem. Sci., 2019, 10, 5743

๑ All publication charges for this article have been paid for by the Royal Society of Chemistry

Received 24th March 2019

Accepted 25th April 2019

DOI: $10.1039 / c 9 s c 01447 \mathrm{k}$

rsc.li/chemical-science

\section{Salting-in species induced self-assembly of stable MOFs'}

\begin{abstract}
Ke Li, Jian Yang and Jinlou Gu (DD *
Metal-organic frameworks (MOFs) are attracting immense research interest despite the fact that their synthesis usually proceeds in organic media or under harsh conditions depending on specific cases. Herein, Hofmeister effect was firstly introduced for the construction of MOFs and thereafter a general salting-in species (SS) induced self-assembly strategy was proposed for the aqueous-phase and mild synthesis of stable MOFs based on a unique "solubilization-mediating" mechanism. The SS not only improved the solubility of organic ligands, but also effectively mediated the mutual proximity of the organic linkers and the inorganic nodes, thus facilitating the crystallization of MOFs under mild conditions. Several typical and highly useful stable MOFs were exemplified owing to the availability of various SS. This strategy could set a framework for the development of more stable MOFs in aqueous phase and drive the large-scale and economic production of MOFs.
\end{abstract}

\section{Introduction}

Metal-organic frameworks (MOFs) are booming as a new class of porous and crystalline materials., ${ }^{\mathbf{1 2}}$ The advent of stable MOFs based on high-valent metal ions has aroused a new research upsurge since more application potentials of this emerging materials become possible. ${ }^{3-8}$ Unfortunately, their traditional synthesis usually suffers from some disadvantages, including the requirement of organic media, harsh conditions as well as toxic additives such as HF. In recent years, there has been an emerging interest in improving the synthesis procedure of MOFs and some significant progress has been made. ${ }^{9-16}$ Herein, we propose a universal salting-in species (SS) induced self-assembly (SSISA) strategy based on the Hofmeister effect to solve the intractable issues. The key to this achievement lies in the roles of SS, which not only promote the gradual dissolution of the organic ligands into the water media, but also mediate the mutual proximity of the organic linkers and the inorganic nodes. ${ }^{17,18}$ Such a unique "solubilization-mediating" mechanism is significantly conducive to increase the reaction probability of the MOF precursors, thus facilitating the aqueousphase construction of the well-crystallized MOFs under mild conditions. We have exemplified the validity of our strategy through the successful synthesis of a series of stable MOFs including UiO-66(Zr) with different topological structures, ${ }^{\mathbf{1 9 , 2 0}}$ UiO-66(Hf), ${ }^{21}$ UiO-66(Ce), ${ }^{22}$ MIL-53(Al),${ }^{23} \mathrm{MIL}-101(\mathrm{Cr}){ }^{24}$ as well as

Key Laboratory for Ultrafine Materials of Ministry of Education, School of Materials Science and Engineering, East China University of Science and Technology, Shanghai 200237, China.E-mail: jinlougu@ecust.edu.cn

$\dagger$ Electronic supplementary information (ESI) available: General methods, synthetic procedures, structural characterization, and additional figures and tables. See DOI: 10.1039/c9sc01447k their derivatives. The specific self-assembly prerequisites of different stable MOFs were met due to the availability of various SS. In most cases, a simple synthesis could be performed as only the precursors of MOFs were required in the presence of SS under mild conditions. Taking UiO-66(Ce) family as an example, the reaction could be completed within $10 \mathrm{~min}$ even at room temperature. We expect that our strategy would present the guidelines for the rational design of a broad variety of stable MOFs with remarkable properties, driving the large-scale utilization of the MOFs towards commercialization.

\section{Results and discussion}

More than a century ago, Hofmeister series was established based on the ability of ions to precipitate proteins. ${ }^{25}$ The typical order of the anion and cation series is shown in Fig. 1a. ${ }^{26}$ Generally, the ions on the left side are called salting-out ions, whereas, those on the opposite side are called salting-in ions. The Hofmeister series has an important effect on the aqueous solubility of the solutes ranging from the small molecules to the biomacromolecules and polymers. For example, 1,4-dicarboxybenzene (BDC) is the most extensively used ligand for the construction of stable MOFs, but it is poorly soluble in aqueous media. The preliminary experiments displayed that the aqueous solubilities of BDC and its derivatives could be enhanced by the salting-in ions $\left(\mathrm{NO}_{3}{ }^{-}, \mathrm{ClO}_{4}{ }^{-}, \mathrm{SCN}^{-}, \mathrm{I}^{-}\right.$and guanidinium $\left(\mathrm{Gdm}^{+}\right)$), whereas, the solubility could be decreased by the salting-out ion $\left(\mathrm{Cl}^{-}\right)$. This was in good line with the Hofmeister effect (Fig. 1b, S1 and S2, see ESI $\dagger$ ). The scientific interpretation of "Hofmeister effect" has experienced continuous revisions. Consensus has currently reached that a direct interaction between the ions and the solutes plays a critical role in the 
a

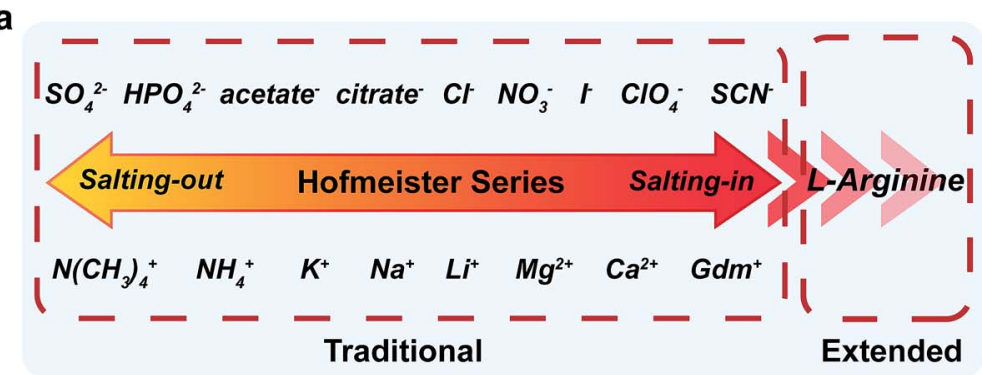

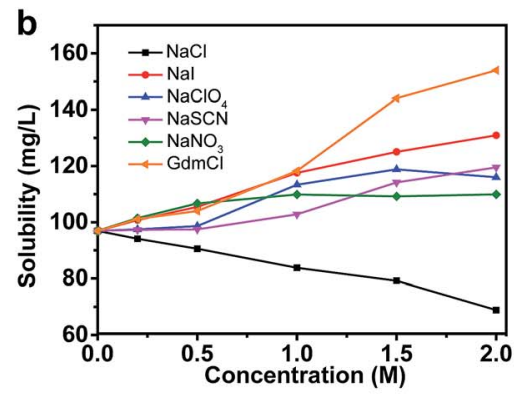

d

c

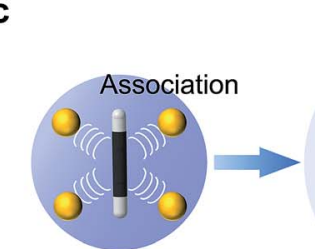

Solubilization

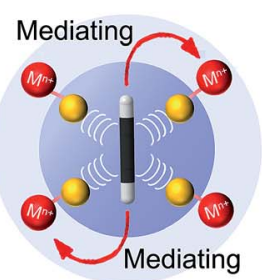

Salting-in Species (SS) BDDC

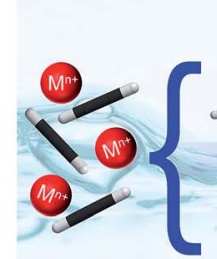

Metal Nodes

e

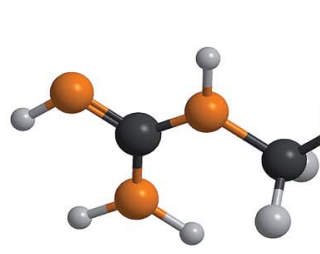

Guanidine Group

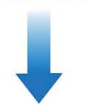

Salting-in Fragment

I

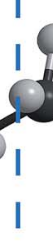

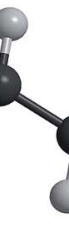
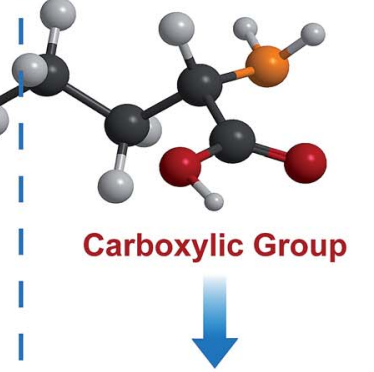

Modulator Fragment
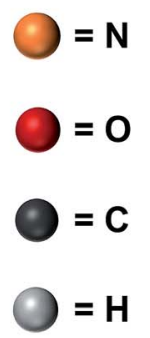

$=\mathrm{H}$

In the Absence of SS
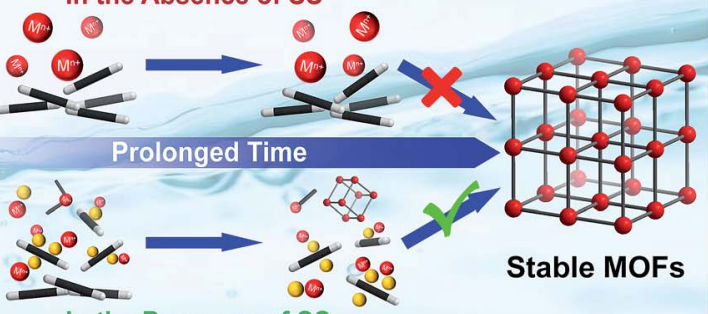

In the Presence of SS

f

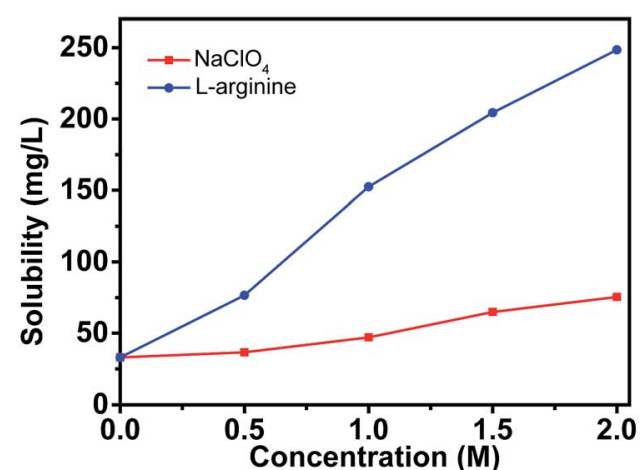

Fig. 1 Illustration of Hofmeister effect, the structures of SS, general route for the SSISA of stable MOFs and solubility measurements: (a) traditional and extended Hofmeister series. (b) Solubility of $\mathrm{BDC}-\mathrm{NH}_{2}$ molecule in the presence of salting-in or salting-out species as a function of their varying concentrations at $\mathrm{pH}$ 6.5. Since Nal, $\mathrm{NaNO}_{3}, \mathrm{NaSCN}$ and $\mathrm{GdmCl}$ present strong absorptions at 200-240 nm, which completely overlap the characteristic absorption of BDC $(240 \mathrm{~nm})$, we only studied their effects on the solubility of BDC-NH $\mathrm{Babsorption}_{2}$ at $\left.329 \mathrm{~nm}\right)$ and presented a qualitative result using orthogonal experiments. (c) Schematic illustration of the solubilization and mediating effects of the SS. (d) Schematic illustration of the SSISA strategy based on Hofmeister effect. (e) Molecular structure of L-arginine. (f) Solubility of BDC in the L-arginine and $\mathrm{NaClO}_{4}$ solutions as a function of their concentrations at $\mathrm{pH} 6.5$.

observed Hofmeister effect. ${ }^{27}$ As far as the SS are concerned, they are readily polarized and substantial dipoles are induced so that they present a high affinity towards the hydrophobic ligands of the MOFs through favorable dipole-dipole interactions. The bound SS weakened the hydrophobic aggregation of the organic ligands, thereby improving their aqueous solubility. ${ }^{28-31}$ It is worth noting that the underlying molecular-level mechanisms of Hofmeister effect is quite complicated and the series of ions may be partially or even completely reversed depending on the size, polarity and charge of the solute or other properties of the solution system. ${ }^{32-34}$ Therefore, the solubilization ability of SS for $\mathrm{H}_{2} \mathrm{BDC}$ did not completely follow the typical Hofmeister ordering (Fig. 1a), but the salting-in and salting-out characteristics of the ions were still consistent with the traditional classification of the Hofmeister effect. In addition to solubilization, the abundant SS that accumulated around the organic ligands would simultaneously attract the metal precursors, acting as the mediators to bridge the organic linkers and the inorganic nodes (Fig. 1c). ${ }^{35}$ The enhancement of the local concentration of the MOF precursors relative to the bulk facilitates the self-assembly of the MOFs under mild conditions. Therefore, the reaction could be triggered even if there were a few dissolved ligands initially. Upon prolonging the reaction time, the undissolved ligands were continuously pumped into the solution to compensate for the ones in the formation of MOFs until they were completely used up. Based on this, we firstly introduced the Hofmeister theory into the selfassembly of MOFs in the aqueous phase, and a unique "solubilization-mediating" mechanism is summarized (Fig. 1c and d).

Additionally, the Hofmeister series could be extended to the organic species for the formation of MOFs (Fig. 1a). ${ }^{36}$ Of special attention is L-arginine owing to its distinctive structural characteristic with both the guanidine and carboxylic groups 
(Fig. 1e). Previous research suggested that the interaction between the guanidine group and the $\pi$-conjugated system endowed L-arginine with a remarkable solubilization capacity for aromatic compounds. ${ }^{37}$ The solubility measurements also confirmed its pronounced salting-in effect than those of the small ions (Fig. 1f and S3 in ESI $\dagger$ ). The bifunctional characteristic means that L-arginine can serve not only as a mediator, but also as a modulator with its carboxyl group binding to the inorganic nodes in MOFs. Based on the above effects, different stable MOFs could be obtained under aqueous and mild conditions simply by mixing appropriate SS with specific MOF precursors.

UiO-66(Zr) was selected as the first research target due to its exceptional stability. Using $\mathrm{NO}_{3}{ }^{-}, \mathrm{ClO}_{4}{ }^{-}, \mathrm{SCN}^{-}, \mathrm{I}^{-}$or $\mathrm{Gdm}^{+}$as a mediator and acetic acid (AA) as a modulator, UiO-66( $\mathrm{Zr}$ ) MOFs adopted an hcp (hexagonal close packing) topology. This could be facilely obtained in an aqueous phase at $90{ }^{\circ} \mathrm{C}$ (Fig. 2a, b and S4-S6 in ESI $\dagger$ ). hcp-UiO-66 is a ligand-deficient analogue to the conventional fcu-UiO-66, while the structure of its secondary building units is $\mathrm{Zr}_{12}\left(\mu_{3}-\mathrm{O}\right)_{8}\left(\mu_{3}-\mathrm{OH}\right)_{8}\left(\mu_{2}-\mathrm{OH}\right)_{6}$. Its structure could be viewed as a fusion of two commonly observed $\mathrm{Zr}_{6}$ clusters. ${ }^{20,38}$ A previous study has reported that the formation of hcp structure was due to the low solubility of the ligands in the synthesis media and the presence of large modulators. ${ }^{38}$ Therefore, the limited solubilization capacity of the applied SS in combination with the AA rationalized the generation of the hcp phase structure by the developed SSISA strategy. The $\mathrm{N}_{2}$-sorption isotherms of hcp-UiO-66-NaI and hcpUiO-66-Gdm exhibited type I isotherms with BET surface area of 895 and $817 \mathrm{~m}^{2} \mathrm{~g}^{-1}$, respectively (Fig. 2c). The SEM and TEM images showed an intergrowth morphology of flat plates of approximately $200 \mathrm{~nm}$ in diameter and $20 \mathrm{~nm}$ in thickness (Fig. 2d and e). These were in good agreement with those typically observed for hcp MOFs. ${ }^{20,38}$ The TGA curve showed that the hcp-UiO-66-NaI was stable up to $450{ }^{\circ} \mathrm{C}$. The weight loss of $39.6 \%$ from 300 to $800{ }^{\circ} \mathrm{C}$ matched well with the theoretical weight loss of $40.5 \%$ based on the conversion of $\mathrm{Zr}_{12} \mathrm{O}_{15}(\mathrm{BDC})_{9}$ to $\left(\mathrm{ZrO}_{2}\right)_{12}$ (see ESI, Fig. S7†).
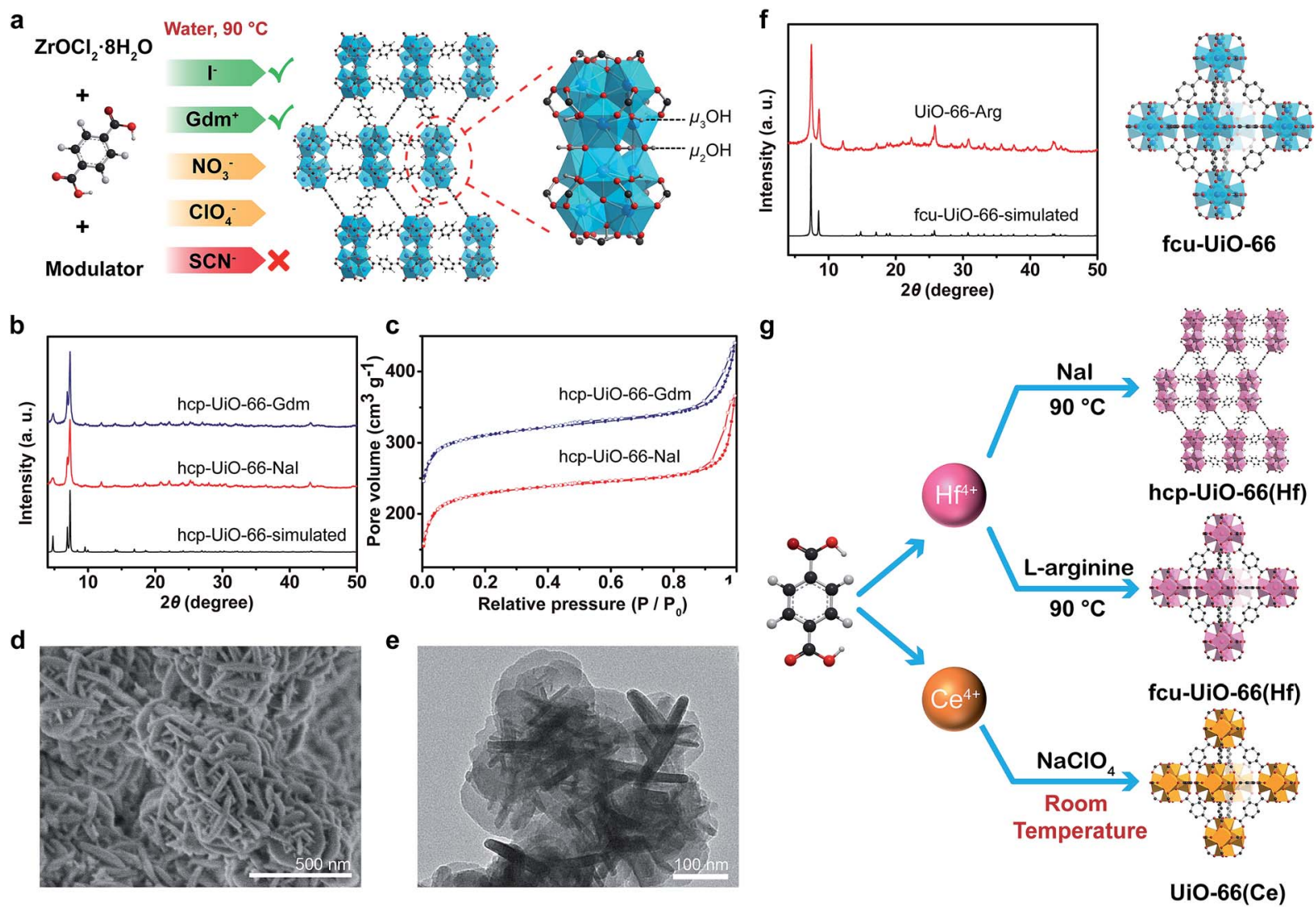

Fig. 2 Schematic illustration and structural and morphological characterizations for the tetravalent metallic MOFs: (a) scheme of the synthesis for hcp-UiO-66(Zr). It should be noted that $\mathrm{Nal}$ and $\mathrm{GdmHCl}$ are recommended because of the low efficiency of $\mathrm{NaNO}_{3}$ and $\mathrm{NaClO}_{4}$, while NaSCN decomposes into toxic species in acidic condition. The middle is the three-dimensional crystal structure of the hcp-UiO-66. Structural view of the $\mathrm{Zr}_{12}\left(\mu_{3}-\mathrm{O}\right)_{8}\left(\mu_{3}-\mathrm{OH}\right)_{8}\left(\mu_{2}-\mathrm{OH}\right)_{6}$ is shown on the right. $\mathrm{Zr}, \mathrm{O}, \mathrm{C}$ and $\mathrm{H}$ are shown in blue, red, grey and white, respectively. (b) XRD patterns of hcp-UiO-66-Nal and hcp-UiO-66-Gdm and a comparison with simulated one of hcp-UiO-66. (c) $\mathrm{N}_{2}$ adsorption (filled circles) and desorption (open circles) isotherms at $77 \mathrm{~K}$ for hcp-UiO-66-Nal and hcp-UiO-66-Gdm. (d) A typical SEM image of the hcp-UiO-66(Zr)-Nal. (e) A typical TEM image of the hcp-UiO-66(Zr)-Nal. (f) XRD pattern of UiO-66(Zr)-arg and a comparison with that of simulated fcu-UiO-66. The crystal model on the right is the structural view of the $\mathrm{UiO}-66(\mathrm{Zr})$ structures adopted an fcu topology. $\mathrm{Zr}, \mathrm{O}, \mathrm{C}$ and $\mathrm{H}$ are shown in blue, red, grey and white, respectively. (g) Scheme of synthesis of $\mathrm{Hf}$ - and Ce-based $\mathrm{UiO}-66 \mathrm{MOFs}$. Hf, Ce, O, C and H are shown in pink, orange, red, grey and white, respectively. 
When L-arginine was applied as a mediator, conventional fcu-UiO-66 structure could be obtained with only eight equivalent L-arginine moieties per $\mathrm{Zr}^{4+}$ ion (Fig. 2f). Given an efficient solubilization of L-arginine, the formation of the fcu rather than hcp phase might be partly attributed to the increase in the dissolved ligand concentration and the decrease in the modulator amount. To verify the dual functions of L-arginine, $\mathrm{GdmCl}$, glycine and lysine were chosen as the additives for the control experiments. The results showed that the addition of $\mathrm{GdmCl}$ without a carboxyl modulator moiety could only produce an amorphous sample. Meanwhile, no product could be obtained in the presence of glycine and lysine due to the lack of the salting-in fragment. The sample synthesized via our SSISA strategy exhibited a BET surface area of $1286 \mathrm{~m}^{2} \mathrm{~g}^{-1}$ and thermal stability similar to the conventional UiO-66 synthesized in organic media. ${ }^{19}$ In addition, ${ }^{1} \mathrm{H}$ NMR spectroscopic analysis showed that no L-arginine was incorporated into UiO-66 structure (see ESI, Fig. S8†).

In addition to zirconium ions, UiO-66-type MOFs can also be synthesized using other tetravalent metal ions such as $\mathrm{Hf}^{18}$ and Ce. ${ }^{22}$ UiO-66(Hf) featured physicochemical properties similar to UiO-66(Zr) because $\mathrm{Hf}$ and $\mathrm{Zr}$ are elements of the same group. The hcp and fcu topologies could be obtained using $\mathrm{NaI}$ and $\mathrm{L}^{-}$ arginine as a mediator, respectively (Fig. $2 g$ and S9 in ESI $\dagger$ ). The UiO-66(Hf) MOFs exhibited a smaller specific surface area than the UiO-66(Zr) counterparts due to the higher atomic mass of $\mathrm{Hf}$ (see ESI, Fig. S9†). The Ce-based UiO-66 was another member of the UiO-66-type MOFs. The initial report for the synthesis of UiO-66(Ce) involved the treatment of ceric(Iv) ammonium nitrate $\left(\left(\mathrm{NH}_{4}\right)_{2} \mathrm{Ce}\left(\mathrm{NO}_{3}\right)_{6}\right)$ and BDC in a mixture of DMF and water at $100{ }^{\circ} \mathrm{C}^{22}$ Herein, using our SSISA strategy, UiO-66(Ce) could be obtained at room temperature with water as the sole solvent (Fig. $2 \mathrm{~g}$ and S10 in ESI $\dagger$ ). Notably, strong oxidative SS such as $\mathrm{NaClO}_{4}$ should be selected in the current case to prohibit the reduction of $\mathrm{Ce}(\mathrm{Iv})$ and to promote the aqueousphase synthesis of MOFs. In contrast, the construction of MOFs could not be realized upon using $\mathrm{NaI}$ as a mediator because of the redox reaction between $\mathrm{I}^{-}$and $\mathrm{Ce}^{4+}$ ions.

Besides the tetravalent metals, trivalent metals are also competent to construct stable MOFs, and typical examples are the MIL series pioneered by Férey and co-workers. ${ }^{23,24}$ Our special interest is in MIL-53(Al), which exhibits breathing effect in the presence of water molecules. ${ }^{23}$ Conventionally, MIL-53(Al) was hydrothermally constructed from $\mathrm{Al}\left(\mathrm{NO}_{3}\right)_{3} \cdot 9 \mathrm{H}_{2} \mathrm{O}$ and BDC at $220{ }^{\circ} \mathrm{C}$ for 3 days. Herein, by simply adding NaI, we successfully prepared MIL-53(Al) at $100{ }^{\circ} \mathrm{C}$ with a shorter time period of $24 \mathrm{~h}$ (Fig. 3a). The XRD pattern of the as-synthesized MIL-53(Al) as matched well with that of the MOFs containing unreacted BDC ligands in the tunnels (Fig. 3b). ${ }^{39,40}$ Replacing $\mathrm{I}^{-}$ with $\mathrm{NO}_{3}{ }^{-}, \mathrm{ClO}_{4}{ }^{-}$or $\mathrm{Gdm}^{+}$ions yielded the same results (see ESI, Fig. S11 $\dagger$ †). After undergoing solvent extraction, the XRD pattern of MIL-53(Al) as evolved into the form of MIL-53(Al) $)_{1 \mathrm{t}}(\mathrm{lt}=$ low temperature) because of the reversible adsorption of water at room temperature (Fig. 3b). Compared to the spectrum of MIL-53(Al) as, the absence of $-\mathrm{COOH}$ absorption at $1700 \mathrm{~cm}^{-1}$ in the FTIR spectrum of MIL-53(Al) $)_{\text {sol }}$ indicated the effective removal of free BDC in tunnels (Fig. 3c). The calculated BET
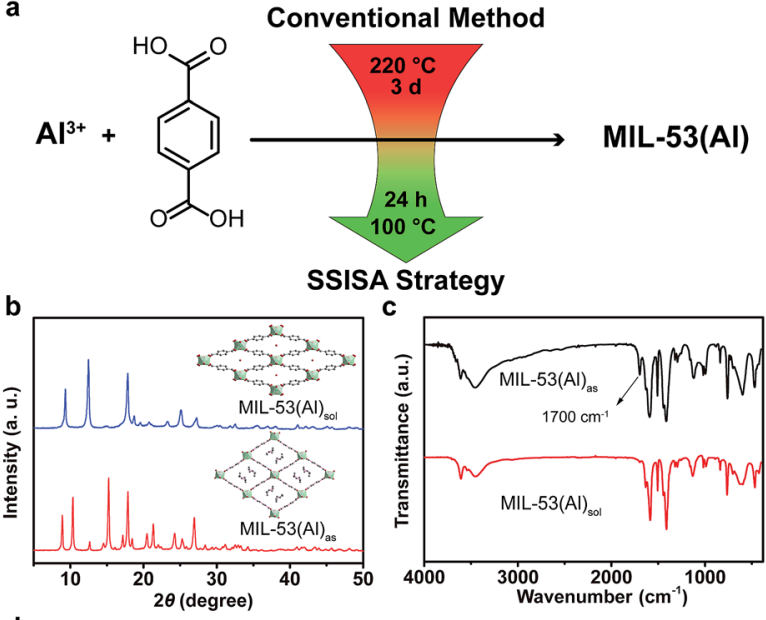

d
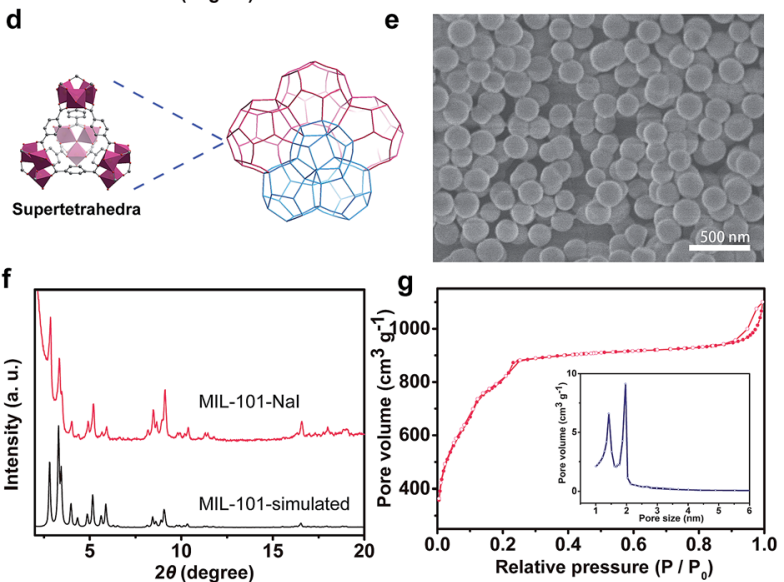

Fig. 3 Schematic illustration and structural characterizations of MIL53(Al) and MIL-101(Cr) synthesized under mild conditions: (a) conditions for obtaining MIL-53(Al) with conventional method and our strategy. (b) XRD patterns of the as-synthesized MIL-53 and after solvent extraction. The bottom inset is the view of the corresponding form of MIL-53(Al) as, in which the channels are occupied by free disordered BDC molecules. The inset above is the view of MIL-53(Al) It at low temperature, in which a water molecule is located at the center of the channels. $\mathrm{Al}, \mathrm{O}$ and $\mathrm{C}$ are shown in green, red and black, respectively. (c) FT-IR spectra of the MIL-53(Al) as (black) and MIL$53(\mathrm{Al})_{\text {sol }}(\mathrm{red})$. The arrow indicates the $-\mathrm{COOH}$ group of the unreacted free BDC molecules encapsulated within the pores. (d) Schematic illustration of the crystal structure of MIL-101(Cr). The hybrid supertetrahedron (ST) building unit is formed by BDC ligands and trimeric chromium(III) octahedral clusters. (e) Typical SEM image of the assynthesized MIL-101 induced by Nal. (f) XRD pattern of MIL-101(Cr)Nal obtained at $120^{\circ} \mathrm{C}$ compared to the simulated one. (g) $\mathrm{N}_{2}$ sorption isotherm of the MIL-101(Cr)-Nal. The inset is the BJH pore size distribution profile with two monodispersed pores peaking at about 14.2 and $19.6 \AA$

surface area was $1564 \mathrm{~m}^{2} \mathrm{~g}^{-1}$, which was higher than that of the reported one. ${ }^{23,39}$ The TGA profile indicated that the sample was thermally stable up to $500{ }^{\circ} \mathrm{C}$, which is consistent with the previous report (see ESI, Fig. S11†). ${ }^{23,39}$

Compared to the thermodynamically favored MOFs mentioned above, MIL-101(Cr) was a kinetic product and the synthesis conditions were subtle. The resulting framework adopted an augmented MTN zeotype topology with two kinds of 
quasi-spherical cages (Fig. 3d). ${ }^{24}$ The significant attraction of MIL-101(Cr) lies in its unusually large pore volume and surface area. Traditionally, MIL-101(Cr) was formed between 180 and $220{ }^{\circ} \mathrm{C}$, involving the use of highly corrosive $\mathrm{HF}$ acid as a mineralizing agent. ${ }^{41}$ Moreover, a significant amount of BDC remained unreacted and trapped in cages, which was difficult to remove and led to the decrease in porosity. Nevertheless, our SSISA strategy also efficiently worked for the synthesis of MIL101(Cr) (see ESI $\dagger$, Section S5.6.1). Assisted with NaI, highly crystallized MIL-101(Cr) could be obtained without HF at a relatively low temperature of $120^{\circ} \mathrm{C}$. The SEM image showed that the size of particles was around $250 \mathrm{~nm}$, and no rod-like byproducts of the recrystallized BDC were observed (Fig. 3e). Their experimental XRD pattern was in agreement with that of the simulated one (Fig. 3f). The $\mathrm{N}_{2}$ sorption isotherm exhibited the characteristic steps of the MIL-101 structure with a high specific BET surface area of $3314 \mathrm{~m}^{2} \mathrm{~g}^{-1}$ (Fig. 3g). When using $\mathrm{GdmCl}$ as a mediator, the produced MOFs were of the similar structure to that prepared using NaI (see ESI, Fig. S15†).

To further illustrate the viability of the strategy, various functionalized BDC ligands were also applied to construct stable MOFs, and here we have presented some typical examples (Fig. 4a). In the presence of SS, UiO-66(Zr) derivatives
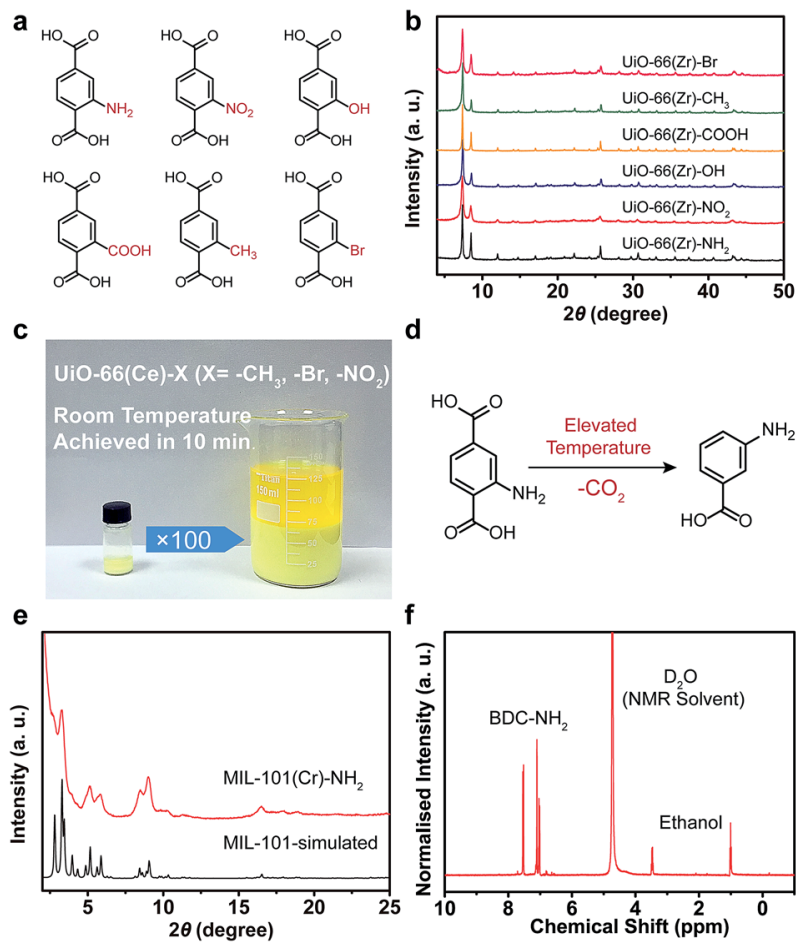

d
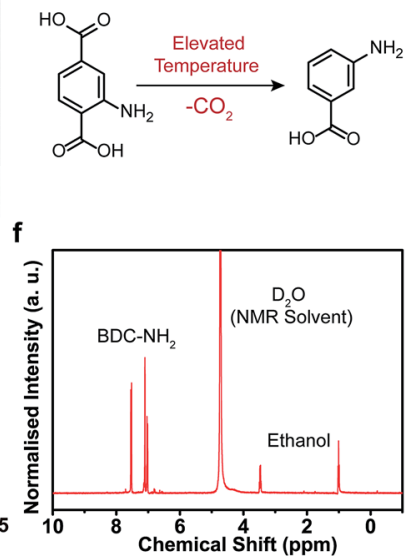

Fig. 4 Extension of the SSISA strategy: (a) structures of the functionalized BDC ligands applied in the current study. (b) XRD patterns of the $\mathrm{UiO}-66(\mathrm{Zr})$ derivatives obtained in the presence of Nal solution. (c) Scale-up synthesis of the $\mathrm{UiO}-66(\mathrm{Ce})-\mathrm{CH}_{3}$ compound via the simple and rapid procedure presented herein and the other derivatives exhibit the similar phenomena. (d) Decarboxylation of $\mathrm{BDC}-\mathrm{NH}_{2}$ taking place at elevated temperature using conventional synthetic method. (e) XRD pattern of the MIL-101(Cr) $-\mathrm{NH}_{2}$ compound synthesized directly at $120{ }^{\circ} \mathrm{C}$ and the simulated result. (f) ${ }^{1} \mathrm{H}$ NMR spectrum of the digested MIL-101- $\mathrm{NH}_{2}$ after extraction. containing $-\mathrm{NH}_{2},-\mathrm{NO}_{2},-\mathrm{OH},-\mathrm{COOH},-\mathrm{CH}_{3}$ and $-\mathrm{Br}$ could be facilely synthesized in an aqueous phase with excellent crystallinity (Fig. 4b, S16, S17 and Table S2 in ESI †े). Notably, the UiO-66(Ce) derivatives containing $-\mathrm{NO}_{2},-\mathrm{CH}_{3}$ and $-\mathrm{Br}$ could be obtained without any additives except SS at room temperature within $10 \mathrm{~min}$. No change in the crystallinity of the product was observed upon scaling-up the synthesis to 100 fold (Fig. 4c and S18, S19 in ESI†). The simple, mild, rapid and aqueous approach made this process feasible for mass production and commercialization. In the case of MIL-101(Cr)- $\mathrm{NH}_{2}$, it was conventionally obtained by the post-synthetic modification due to the easy decomposition of $\mathrm{BDC}-\mathrm{NH}_{2}$ ligand at elevated temperatures (Fig. 4d). Using the SSISA strategy, the direct synthesis of MIL-101(Cr)- $\mathrm{NH}_{2}$ was successfully realized at $120{ }^{\circ} \mathrm{C}$ with the aid of $\mathrm{GdmCl}$ as a mediator. A slightly broadened Bragg reflection was observed due to the small particle size of the resulting sample (Fig. 4e and S20a in ESI †). The specific surface area of the sample reached a satisfactory value of 2947 $\mathrm{m}^{2} \mathrm{~g}^{-1}$ (see ESI, Fig. S20b $\dagger$ ). The ${ }^{1} \mathrm{H}$ NMR spectrum showed that $\mathrm{BDC}-\mathrm{NH}_{2}$ ligand was intact without any decomposition (Fig. $4 \mathrm{f})^{42}$

\section{Conclusions}

In summary, Hofmeister effect is firstly introduced to rationalize the crystallization of stable MOFs in aqueous phase and thereafter a general SSISA strategy is proposed based on a unique "solubilization-mediating" mechanism. Several typical and useful stable MOFs are exemplified to validate the reproducibility of our strategy. The SSISA strategy could not only simplify the traditional organic-phase self-assembly process of MOFs (e.g., low temperature, rapid reaction rate, no mineralizer and green solvent), but also help realize the formation of different phase structures (e.g., hcp-UiO-66 and fcu-UiO-66). This study, we believe, would pave the way for the large-scale and economic production of the MOFs. Further extension of this strategy can provide a new perspective for the development of a broad variety of new stable MOFs in aqueous phase.

\section{Conflicts of interest}

There are no conflicts to declare.

\section{Acknowledgements}

This work was financially supported by the Natural Science Foundation of Shanghai (18ZR1408700), Projects of Shanghai Municipality (18JC1410802), the National Key Research and Development Program (2016YFC1102100), 111 Project (B14018) and Natural Science Foundation of China (51372084).

\section{Notes and references}

1 H. Furukawa, K. E. Cordova, M. O'Keeffe and O. M. Yaghi, Science, 2013, 341, 1230444.

2 J. R. Long and O. M. Yaghi, Chem. Soc. Rev., 2009, 38, 1213. 
3 S. Yuan, L. Feng, K. Wang, J. Pang, M. Bosch, C. Lollar, Y. Sun, J. Qin, X. Yang, P. Zhang, Q. Wang, L. Zou, Y. Zhang, L. Zhang, Y. Fang, J. Li and H.-C. Zhou, Adv. Mater., 2018, 30, 1704303.

4 C. Wang, X. Liu, N. K. Demir, J. Paul Chen and K. Li, Chem. Soc. Rev., 2016, 45, 5107.

5 J. Liu, L. Chen, H. Cui, J. Zhang, L. Zhang and C.-Y. Su, Chem. Soc. Rev., 2014, 43, 6011J; A. Mason, M. Veenstra and J. R. Long, Chem. Sci., 2013, 5, 32.

6 W. P. Lustig, S. Mukherjee, N. D. Rudd, A. V. Desai, J. Li and S. K. Ghosh, Chem. Soc. Rev., 2017, 46, 3242.

7 S. M. Cohen, Chem. Sci., 2010, 1, 32.

8 A. J. Howarth, Y. Liu, P. Li, Z. Li, T. C. Wang, J. T. Hupp and O. K. Farha, Nat. Rev. Mater., 2016, 1, 15018.

9 N. Stock and S. Biswas, Chem. Rev., 2012, 112, 933.

10 P. A. Julien, C. Mottillo and T. Friščić, Green Chem., 2017, 19, 2729.

11 P. Silva, S. M. F. Vilela, J. P. C. Tomé and F. A. A. Paz, Chem. Soc. Rev., 2015, 44, 6774.

12 Y. Bai, Y. Dou, L.-H. Xie, W. Rutledge, J.-R. Li and H.-C. Zhou, Chem. Soc. Rev., 2016, 45, 2327.

13 Z. Ajoyan, P. Marino and A. J. Howarth, CrystEngComm, 2018, 20, 5899.

14 I. Pakamorè, J. Rousseau, C. Rousseau, E. Monflier and P. Ágota Szilágyi, Green Chem., 2018, 20, 5292.

15 M. R. DeStefano, T. Islamoglu, S. J. Garibay, J. T. Hupp and O. K. Farha, Chem. Mater., 2017, 29, 1357.

16 K. Guesh, C. A. D. Caiuby, Á. Mayoral, M. Díaz-García, I. Díaz and M. Sanchez-Sanchez, Cryst. Growth Des., 2017, 17, 1806.

17 D. J. Tobias and J. C. Hemminger, Science, 2008, 319, 1197.

18 Y. Zhang, S. Furyk, D. E. Bergbreiter and P. S. Cremer, J. Am. Chem. Soc., 2005, 127, 14505.

19 J. H. Cavka, S. Jakobsen, U. Olsbye, N. Guillou, C. Lamberti, S. Bordiga and K. P. Lillerud, J. Am. Chem. Soc., 2008, 130, 13850.

20 M. Ermer, J. Mehler, M. Kriesten, Y. S. Avadhut, P. S. Schulz and M. Hartmann, Dalton Trans., 2018, 47, 14426.

21 S. Jakobsen, D. Gianolio, D. S. Wragg, M. H. Nilsen, H. Emerich, S. Bordiga, C. Lamberti, U. Olsbye, M. Tilset and K. P. Lillerud, Phys. Rev. B: Condens. Matter Mater. Phys., 2012, 86, 125429.

22 M. Lammert, M. T. Wharmby, S. Smolders, B. Bueken, A. Lieb, K. A. Lomachenko, D. De Vos and N. Stock, Chem. Commun., 2015, 51, 12578.

23 Y. Liu, J.-H. Her, A. Dailly, A. J. Ramirez-Cuesta, D. A. Neumann and C. M. Brown, J. Am. Chem. Soc., 2008, 130, 11813.
24 G. Férey, C. Mellot-Draznieks, C. Serre, F. Millange, J. Dutour, S. Surblé and I. Margiolaki, Science, 2005, 309, 2040.

25 F. Hofmeister, Archiv fur Experimentelle Pathologie und Pharmakologie, 1888, 24, 247.

26 H. I. Okur, J. Hladílková, K. B. Rembert, Y. Cho, J. Heyda, J. Dzubiella, P. S. Cremer and P. Jungwirth, J. Phys. Chem. $B, 2017,121,1997$.

27 P. Jungwirth and P. S. Cremer, Nat. Chem., 2014, 6, 261.

28 M. C. Gurau, S.-M. Lim, E. T. Castellana, F. Albertorio, S. Kataoka and P. S. Cremer, J. Am. Chem. Soc., 2004, 126, 10522.

29 R. Zangi, M. Hagen and B. J. Berne, J. Am. Chem. Soc., 2007, 129, 4678.

30 L. I. N. Tomé, F. R. Varanda, M. G. Freire, I. M. Marrucho and J. A. P. Coutinho, J. Phys. Chem. B, 2009, 113, 2815.

31 N. O. Johnson, T. P. Light, G. MacDonald and Y. Zhang, J. Phys. Chem. B, 2017, 121, 1649.

32 E. A. Algaer and N. F. A. van der Vegt, J. Phys. Chem. B, 2011, 115, 13781.

33 S. Endo, A. Pfennigsdorff and K.-U. Goss, Environ. Sci. Technol., 2012, 46, 1496.

34 M. Boström, D. F. Parsons, A. Salis, B. W. Ninham and M. Monduzzi, Langmuir, 2011, 27, 9504.

35 S. Pal and F. Müller-Plathe, J. Phys. Chem. B, 2005, 109, 6405.

36 P. H. Yancey, M. E. Clark, S. C. Hand, R. D. Bowlus and G. N. Somero, Science, 1982, 217, 1214.

37 A. Hirano, T. Kameda, T. Arakawa and K. Shiraki, J. Phys. Chem. B, 2010, 114, 13455.

38 M. J. Cliffe, E. Castillo-Martínez, Y. Wu, J. Lee, A. C. Forse, F. C. N. Firth, P. Z. Moghadam, D. Fairen-Jimenez, M. W. Gaultois, J. A. Hill, O. V. Magdysyuk, B. Slater, A. L. Goodwin and C. P. Grey, J. Am. Chem. Soc., 2017, 139, 5397.

39 T. Loiseau, C. Serre, C. Huguenard, G. Fink, F. Taulelle, M. Henry, T. Bataille and G. Férey, Chem.-Eur. J., 2004, 10, 1373.

40 A. M. Walker, B. Civalleri, B. Slater, C. Mellot-Draznieks, F. Corà, C. M. Zicovich-Wilson, G. Román-Pérez, J. M. Soler and J. D. Gale, Angew. Chem., Int. Ed., 2010, 49, 7501.

41 D.-Y. Hong, Y. K. Hwang, C. Serre, G. Férey and J.-S. Chang, Adv. Funct. Mater., 2009, 19, 1537.

42 M. Lammert, S. Bernt, F. Vermoortele, D. E. De Vos and N. Stock, Inorg. Chem., 2013, 52, 8521. 